\title{
Pra lá do mundo existe um mundo comum: um estudo sobre relações entre turistas e moradores do Vale do Capão (Bahia/Brasil)
}

\section{There is a common world in the world: a study on relations between tourists and residents of the Capão Valley (Bahia/Brazil)}

\author{
Isabela Andrade de Lima Morais (MORAIS, I. A. de L.) ${ }^{*}$ e \\ Matí Marques Acioly (ACIOLY, M. M.) ${ }^{* *}$
}

\begin{abstract}
RESUMO - Neste artigo se analisa as relações desenvolvidas entre os turistas e os moradores do Vale do Capão (situado na Chapada Diamantina - Bahia - Brasil). Um lugar que possui muitos atrativos naturais e que recentemente tem desenvolvido a atividade turística, sendo conhecido pelo desenvolvimento do ecoturismo, turismo de natureza, turismo de aventura, turismo esotérico, turismo místico e turismo alternativo. É um estudo de caso de natureza qualitativa, realizado através de pesquisas de campo e de entrevistas entre moradores e turistas realizadas entre os anos de 2015 e 2016, com o objetivo de entender as relações de proximidade e os conflitos existentes entre os moradores e os turistas no Vale do Capão. A imagem turística real e social - do Vale do Capão possui elementos contrastivos, acarretando diversos conflitos e contradições entre os moradores e os turistas e é importante entender esses conflitos para uma proposta de organização sustentável integrada da atividade turística com os desejos dos moradores locais.
\end{abstract}

Palavras-chave: Turismo; Conflito; Imagem; Vale do Capão.

ABSTRACT - This article analyzes the relations developed between the tourists and the residents of the Capão Valley (located in Chapada Diamantina - Bahia - Brazil). A place that has many natural attractions and has recently developed tourism, being known for the development of ecotourism, nature tourism, adventure tourism, esoteric tourism, mystical tourism and alternative tourism. It is a case study of a qualitative nature, carried out through field surveys and interviews between residents and tourists conducted between 2015 and 2016, in order to understand the proximity relations and conflicts between residents and tourists in the Capão Valley. The real and social tourist image of the Capão Valley has contrastive elements, causing several conflicts and contradictions between the residents and the tourists and it is important to understand these conflicts for a proposal of integrated sustainable organization of the tourist activity with the wishes of the local residents.

Key words: Tourism; Conflict; Image; Capão Valley.

\footnotetext{
"Formação: Graduação em História pela Universidade Federal Rural de Pernambuco (UFRPE), Mestrado em Antropologia pelo Programa de Pós-Graduação em Antropologia da Universidade Federal de Pernambuco (UFPE) e Doutorado em Antropologia pelo Programa de Pós-Graduação em Antropologia da Universidade Federal de Pernambuco (UFPE). Atividade profissional: Professora Adjunta do Departamento de Hotelaria e Turismo da Universidade Federal de Pernambuco. Endereço físico para correspondência: Avenida Prof. Moraes Rêgo, 1235, Cidade Universitária. CEP: 50670-901 - Recife Pernambuco - Brasil. E-mail: isabelamorais.ufpe@gmail.com

*** Formação: Graduação em Turismo pelo Departamento de Hotelaria e Turismo da Universidade Federal de Pernambuco (UFPE). Endereço físico para correspondência: Avenida Prof. Moraes Rêgo, 1235, Cidade Universitária. CEP: 50670-901 - Recife - Pernambuco - Brasil. E-mail: mati.simplesmente@gmail.com
} 


\section{INTRODUÇÃO}

O Distrito de Caeté-Açu, ou Vale do Capão, ou simplesmente Capão, está situado na Chapada Diamantina - na Bahia (Brasil) e é conhecido como um "lugar fora do mundo", procurado por seus atrativos naturais e por pessoas que buscam um estilo de vida mais saudável, segundo relato de M.T., Diretor da Associação de Condutores de Visitantes do Vale do Capão - ACV-VC, em entrevista realizada no dia 07 de janeiro de 2016.

As transformações na Chapada Diamantina começaram a partir da criação do Parque Nacional em 1985, impulsionando a oferta turística do local e trazendo grande especulação imobiliária aos municípios localizados ao redor das áreas de conservação ambiental, incluindo o Vale do Capão, quando teve início os primeiros serviços turísticos e o começo da demanda voltada para o ecoturismo e turismo de natureza. Com o seguir dos anos a localidade começou a ser conhecida por sua oferta de vida alternativa à sociedade de consumo, aliadas as vivências de cunho espiritual, como o Santo Daime, as Danças Sagradas e ao desenvolvimento da medicina holística (informações obtidas com M.T., Diretor da Associação de Condutores de Visitantes do Vale do Capão - ACV-VC, em entrevista realizada no dia 07 de janeiro de 2016.

De acordo com H.R., da Associação de Pais, Educadores e Agricultores de Caeté Açu - APEA-CA (em entrevista realizada no dia 06 de janeiro de 2016), o Vale do Capão estava possuindo uma população fixa de 1.655 (um mil seiscentos e cinquenta e cinco) habitantes e recebendo, em média, 2.000 (dois mil) turistas durante os grandes feriados como São João ( 24 de junho) e Réveillon (31 de dezembro). Um número bastante alto para a infraestrutura local e também para a capacidade de carga das trilhas ecológicas localizadas no território pertencente ao Parque Nacional.

O Vale do Capão possui uma população rural tradicional, com heranças culturais do ciclo do café e do diamante, onde predomina a economia de subsistência, sobremodo, de agropecuária e somente mais recentemente da atividade turística (NOGUEIRA, 2003). Dentro deste âmbito, de um lado encontra-se os moradores formado por pequenos agricultores, comerciantes e pessoas envolvidas na atividade turística, essas, tendo um grande poder de articulação para o desenvolvimento da atividade de ecoturismo. Do outro lado, existem três demandas reais: o ecoturismo, o turismo de natureza e o turismo esotérico/místico. 
Da relação estabelecida entre os turistas e os moradores do Vale do Capão, percebeu-se uma contradição entre a vida cotidiana do Vale do Capão (imagem real) e a vida almejada pelos turistas e visitantes (imagem criada, imagem social), gerando contradições e conflitos entre os moradores e os "de fora". A criação da imagem social é de grande relevância na construção e no desenvolvimento de um destino turístico, pois é a propaganda "boca a boca" do local.

Face ao exposto, neste artigo se propõe investigar quais estavam sendo as contradições e conflitos entre os turistas e os moradores no Vale do Capão, decorrentes da divulgação da imagem turística do local.

\section{ANTROPOLOGIA DO TURISMO: ANÁLISES SOBRE A RELAÇÃO ENTRE VISITANTES E VISITADOS}

As análises sobre as relações entre visitantes e visitados estão presentes na antropologia do turismo. Verificou-se que as primeiras pesquisas neste campo se deram a partir de 1950 e 1960 focalizando os impactos econômicos e sociais da atividade turística. Uma das precursoras a analisar o turismo foi Valene Smith, que em 1974 apresentou no encontro da Associação Americana de Antropologia, na cidade do México, o livro Hosts and guests: the anthropology of tourism, inaugurando as análises sociais e antropológicas sobre o turismo (SMITH, 1989).

Graburn (2009, p. 16 -17) elabora uma análise sobre as primeiras pesquisas antropológicas sobre o turismo e, divide-as em quatro tipos básicos:

1) Descoberta empírica: início da década de 1960, quando os antropólogos começam a se preocupar com a intromissão dos turistas em seus trabalhos de campo e passam a documentar os impactos desses visitantes. Podendo-se citar como exemplo do estudo realizado por Theron Nuñez em 1963 ao estudar o turismo em uma vila mexicana.

2) Trabalho em temas afins: antropólogos que escreviam sobre determinados fenômenos e estudos de caso que somente posteriormente foram reconhecidos como contribuições à antropologia do turismo. Como exemplo o estudo de Cohen (1971), Moços árabes e moças turistas, sobre as relações de gênero e das poucas perspectivas para os jovens israelitas. 
3) Extensão teórica: quando foi percebida a disseminação global do turismo, alguns antropólogos analisaram tal fenômeno através de modelos antropológicos já existentes, por exemplo, comparando o turismo a rituais tradicionais ou religiosos, ou incorporando conceitos de aculturação nas pesquisas de impactos de interações sociais, a exemplo dos estudos de Theron Nuñez (1963) e Valene Smith (1989).

4) Análise crítica: quando foram publicadas pesquisas questionando a racionalidade econômica do turismo e suas consequências sociais e culturais, a exemplo dos estudos de Bryden (1973) e Young (1973). Surgiram as primeiras preocupações com a degradação da cultura e da identidade que o turismo provoca.

No entanto, os primeiros estudos da antropologia do turismo foram voltados a analisar os impactos entre os turistas e a sociedade receptora e como este impacto trazia consequências avassaladoras para os visitados. As análises sobre impactos sociais, culturais e ambientais nas comunidades anfitriãs fizeram parte do campo de pesquisa das primeiras etnografias sobre o turismo, e o tema mais discutido era o modelo de aculturação (GRABURN, 2009, p. 19). Essas análises primárias serviram de modelos para trabalhos mais abrangentes em relação às mudanças sociais e culturais provocadas pelo desenvolvimento do turismo. Estes estudos de impacto percebiam apenas dois elementos envolvidos: o turista como o vetor de mudança ativo e a comunidade local como receptor passivo, no qual seu modo de vida era irreparavelmente alterado.

Graburn (2009) revela que posteriormente os estudiosos de antropologia do turismo perceberam que o encontro entre visitantes e visitados nunca é somente uma troca direta, e que tanto as influências externas quanto a comunidade local são complexas e atuantes no jogo de relacionamento. Estudos mais recentes mostram que o termo impacto deve ser percebido moderadamente e que nem sempre as consequências precisam ser negativas, em muitos casos podem ser sinônimos de reforço cultural, identitário e financeiro à comunidade.

O espaço turístico começa a ser percebido como algo que traz "além de uma multiplicidade de referências culturais, uma multiplicidade de práticas que dão sentidos aos lugares, não sentidos de uma identidade unívoca, mas polissêmica" (SANTOS, 2009, p. 138). Assim o lugar antes somente um destino turístico, torna-se um local de trocas de valores e intercâmbios culturais, um lugar híbrido. 
Contudo, mesmo que no momento vigente sejam analisados os processos de atuação da comunidade local perante o desenvolvimento do turismo no destino, em nenhum momento deve ser descartado que a demanda turística, na maioria das vezes, ocorre de maneira agressiva e é capaz de impor novas culturas e novos modos de vida que a população local talvez não esteja preparada para receber.

Referente ao encontro entre visitantes e visitados, Krippendorf (2001, p. 83) enfatiza que este acontecimento segue uma lógica de clichê dotado de relacionamentos artificiais e egocêntricos, onde a cultura de fora acaba por dominar para que exista a comercialização do destino. Tende-se a esquecer que viajantes e anfitriões encontram-se em situações diferentes e mesmo opostas. O tempo livre de um é o trabalho do outro, "o turista que, eventualmente, procura algo mais, esquece, frequentemente, que a experiência única que ele vive representa, para o autóctone, a repetição contínua das mesmas situações" (KRIPPENDORF, 2001, p. 84). Tal situação vai gerando uma saturação ao morador local, que em algum momento acaba por se rebelar com o turista.

Ao abordar as relações entre visitantes e visitados Barretto (2007, p. 61) afirma que muitas vezes existe a criação fantasiosa das comunidades turísticas e comunidades locais onde não existem interações reais e sim uma mera representação dos desejos e anseios do turista para com o destino visitado. Esta situação torna o ambiente propício à conflitos, uma vez que visitantes e anfitriões não compactuam de uma mesma realidade (mundo das ideias versus mundo real).

A relação entre turismo e comunidade local varia de acordo com o tipo de turista que chega ao destino e sua carga histórica e cultural. Além disso, esta relação está intimamente relacionada com as perspectivas (imagem social) que os turistas carregam sobre o local que, por muitas vezes, contrastam com a realidade do lugar e de seus moradores.

\section{A IMAGEM REAL E A IMAGEM SOCIAL DO VALE DO CAPÃO}

O marketing turístico é percebido como:

\footnotetext{
Um processo administrativo através do qual as empresas e outras organizações de turismo identificam seus clientes (turistas), reais e potenciais, e com eles se comunicam para conhecerem e influenciarem suas
} 
necessidades, desejos e motivações nos planos local, regional, nacional e internacional em que atuam, com o objetivo de formular e adaptar seus produtos para alcançar a satisfação ótima da demanda (BENI, 2002, p. 207).

Ele é desenvolvido de acordo com o que a administração local almeja como destino turístico, criando assim uma imagem oficial do lugar, como ocorreu, por exemplo, com algumas cidades litorâneas nordestinas no final dos anos de 1990 com o processo de turistificação dos espaços litorâneos, onde, na concorrência e disputa por visitantes, os governos locais juntamente com o trade turístico investiram no marketing turístico, cidades como Fortaleza (Ceará) ganha uma intensa propaganda turística que a consolida como cidade de "sol e mar" (VIANA, 2012) e a cidade de São Miguel do Gostoso (Rio Grande do Norte) passa a ser conhecida como um "paraíso turístico", destinado ao descanso, a contemplação da natureza e a prática de esportes de aventura (TAVEIRA, 2016).

Como contraponto ao marketing turístico existe o marketing social, mais conhecido como "boca a boca". De acordo com o Urry (1990, p. 28) é necessário entender quais as situações em que se produz um olhar turístico diferenciado, ou seja, é fundamental perceber que experiências turísticas estão relacionadas às experiências prazerosas que, muitas vezes, não são encontradas no cotidiano comum. Assim, a imagem de um destino vai sendo criada e moldada de acordo com as sensações vivenciadas no lugar, mesmo que essa imagem não corresponda ao dia a dia do lugar, portanto, a imagem social é criada independentemente do marketing oficial e segue sua linha própria em combinação com as percepções do próprio turista.

Contudo se faz necessário defender que o olhar do turista não é algo pessoal, criado apenas pelo turista. O devaneio transcende de algo individual para uma atividade socialmente organizada e divulgada massivamente através de propagandas de TV, da literatura, do cinema etc. (URRY, 1990, p. 118). Neste caso os agentes locais, em algum momento, também são responsáveis pela criação da imagem pelo visitante, pois fazem parte da encenação para que a paisagem vendida seja a melhor paisagem, um jogo teatral mostrando uma imagem que mesmo que não seja o real, é a imagem que o turista quer comprar.

Este jogo de criação de imagens é amplamente trabalhado no pós-modernismo que problematiza a distinção entre as representações e a realidade, a simulação ocorre e é tão perfeitamente aceita e até muitas vezes confundida com o natural que assim acaba 
por fazer parte do cotidiano como algo comum, sem que os turistas percebam que aquilo que enxergam não é o real e sem que a comunidade local perceba que está vendendo algo que talvez no futuro não faça mais sentido, pois é um simulacro e não a realidade vivida cotidianamente. De acordo com Urry (1990, p. 122):

\begin{abstract}
Aquilo que as pessoas "contemplam" são representações ideais da visita em questão e que elas internalizam a partir dos cartões postais, dos guias de viagem e, cada vez mais, dos programas de televisão. Mesmo quando elas não conseguem "ver" de fato a maravilha natural em questão, ainda podem senti-la, vê-la em suas mentes. Mesmo quando o objeto deixa de corresponder a sua representação, é esta última que permanecerá na mente das pessoas, como aquilo que elas "viram" de verdade.
\end{abstract}

Urry (1990, p. 134) menciona ainda que a imagem social de um destino turístico muitas vezes é romantizada pelo olhar dos turistas, sobretudo por aqueles turistas que detêm um maior capital cultural. Neste contexto a imagem do campo, da vida rural são objetos cada vez mais atraentes e romantizados para este tipo de público que está à procura de novas formas de consumismo e viram adeptos a estilos de vida alternativos. A vida no campo passa a ser percebida como um espetáculo e seus moradores como os agentes criadores da imagem fantasiada pelo turista, uma imagem que, muitas vezes não corresponde à imagem real do lugar, que foi e é constantemente modificada em virtude das relações que os moradores estabelecem com a atividade turística.

Tanto os turistas como os moradores entrevistados para esta pesquisa relataram a existência de uma imagem social do Vale do Capão como um lugar "fora do mundo", permissivo, sem regras, com estilo de vida alternativo, hippie, esotérico e místico. Identificou-se que essa imagem social estava contrastando com a perspectiva dos moradores em relação ao turismo como uma atividade econômica, e isso acabava, por muitas vezes, em conflitos com os "de fora".

\title{
4 PROCEDIMENTOS METODOLÓGICOS
}

Para analisar as relações desenvolvidas entre moradores e turistas, foi realizada uma pesquisa de natureza qualitativa e descritiva que teve como objetivo principal traduzir e expressar o sentido dos fenômenos da sociedade; trata-se de reduzir a distância entre pesquisador e pesquisado, teoria e dados, contexto e ação, segundo 
Maanen (1979), e expor características de determinada sociedade e fenômeno. A pesquisa foi dividida em três etapas: pesquisa bibliográfica, análise documental e pesquisa de campo. Na pesquisa bibliográfica foram utilizados os livros e periódicos disponíveis nas bibliotecas da Universidade Federal de Pernambuco - UFPE, como também na base de dados da Coordenação de Aperfeiçoamento de Pessoal de Nível Superior - CAPES, e outras bases internacionais de consulta bibliográfica através da internet. A análise documental se deu através de documentos de órgãos oficiais e também através de coleta de imagens antigas do Vale do Capão.

A pesquisa de campo se realizou no início do mês de dezembro (2015) e terminou após o carnaval (fevereiro de 2016), temporada na qual existe grande quantidade de turistas e eventos como o Réveillon e a Festa de Janeiro (festa do padroeiro). A coleta dos dados ocorreu através de entrevistas semiestruturadas realizadas com os diferentes agentes envolvidos, este tipo de abordagem traz perguntas abertas, existindo assim a liberdade do entrevistador para o acréscimo de novas questões e "consiste de uma conversação informal com perguntas abertas ou de sentido genérico, proporcionando maior liberdade para o entrevistado" (FONSECA, 2009, p. 37).

Em relação às entrevistas foram feitas estruturas diferentes de acordo com o perfil do entrevistado: um tipo de entrevista foi realizado com os moradores locais e outro tipo com os turistas. No total foram entrevistados dez turistas e dez moradores locais, conforme quadro 1 abaixo:

QUADRO 1 - RELAÇÃO DE MORADORES E TURISTAS ENTREVISTADOS

\begin{tabular}{|l|c|c|c|}
\hline \multicolumn{1}{|c|}{ Comunidade local } & $\begin{array}{c}\text { Data de } \\
\text { entrevista }\end{array}$ & Turistas & $\begin{array}{c}\text { Data da } \\
\text { entrevista }\end{array}$ \\
\hline A. R. & $04 / 01 / 2016$ & Turista A & $06 / 01 / 2016$ \\
\hline D. A. & $02 / 01 / 2016$ & Turista B & $07 / 01 / 2016$ \\
\hline E. R. & $05 / 01 / 2016$ & Turista C & $05 / 01 / 2016$ \\
\hline M. S. & $05 / 01 / 2016$ & Turista D & $06 / 01 / 2016$ \\
\hline S. S. & $05 / 01 / 2016$ & Turista E & $06 / 01 / 2016$ \\
\hline H. R., diretora da APEACA & $06 / 01 / 2016$ & Turista F & $06 / 01 / 2016$ \\
\hline M. T., diretor da ACV-VC & $07 / 01 / 2016$ & Turista G & $06 / 01 / 2016$ \\
\hline C. S. & $07 / 01 / 2016$ & Turista H & $06 / 01 / 2016$ \\
\hline G. O. & $02 / 01 / 2016$ & Turista I & $07 / 01 / 2016$ \\
\hline V. O. & $05 / 01 / 2016$ & Turista J & $07 / 01 / 2016$ \\
\hline
\end{tabular}

FONTE: Pesquisa de campo (2015-2016).

As entrevistas com os moradores locais levaram em conta pessoas de perfis e idades diferentes. Com relação aos turistas buscaram-se dois perfis diferentes, os 
visitantes que haviam chegado ao Vale do Capão através de receptivos e realizavam passeios no local contratando guias de turismo e os visitantes que optavam por conhecer o local se autoguiando.

Também foi utilizada para a coleta de dados a busca de informações através da observação participante que dá acesso ao observador a participação nos acontecimentos ocorridos no campo de pesquisa. Uma pesquisa de campo:

\begin{abstract}
Consiste na participação real do conhecimento na vida da comunidade, do grupo ou de uma situação determinada. Nesse caso, o observador assume, pelo menos até certo ponto, o papel de um membro do grupo. O observador participante enfrenta grandes dificuldades para manter a objetividade, pelo fato de exercer influência no grupo, ser influenciado por antipatias ou simpatias pessoais e pelo choque do quadro de referência entre observador e observação (PRODANOV; FREITAS, 2013, p. 105).
\end{abstract}

No tratamento e análise dos dados (documentais e de campo) coletados para a pesquisa foi empregada a análise de conteúdo do tipo categorial (BARDIN, 2009).

\title{
5 O TURISMO NO VALE DO CAPÃO E SUAS DIFERENTES IMAGENS
}

Constatou-se que a maioria dos moradores do Vale do Capão não estava percebendo mais o lugar como uma zona rural e estavam cientes da transformação de "rural a turístico" e começavam a ter outra imagem sobre a vida vigente no local. M. e E., nascidos, crescidos e casados no Capão corroboraram com essa afirmação, $M$. relatou: "acho que o Capão já saiu desta fase de rural, de agricultura, dessas coisas, acho que o pessoal já não vive mais disso, tudo gira em torno mais do turismo, dos visitantes. Mas quanto ao Capão ser hippie isso já é uma ideia que colocam”.

Os turistas possuíram opiniões próprias e diversas sobre como enxergavam o lugar visitado, entretanto, em relação ao Capão, a imagem de um lugar alternativo era comum entre os entrevistados. Oito dos turistas entrevistados afirmaram que o Vale do Capão trazia a ideia de um lugar "alternativo". A da turista A. que utilizou serviços turísticos (receptivo, guia, hospedagem etc.), trazia em seu imaginário uma representação do Capão como "a imagem de um lugar mais alternativo, eu já conheço Lençóis e Mucugê, aqui só tinha a vontade de vir e fui deixando, deixando e agora deu”. Já a turista B., que visitava o Vale do Capão há dez anos, comentou: “é um lugar de 
tranquilidade, mas que também tem diversidade cultural, então assim, é o que diferencia dos outros lugares da Chapada".

Sobre a imagem real e imagem turística do Vale do Capão, H. R. Diretora da Associação de Pais, Educadores e Agricultores de Caeté-Açu (APEA-CA), nascida no Capão, não via tanto conflito entre o "Capão vivido" e o "Capão vendido", afirmando que a imagem que se criava do local dependia do convívio de cada um:

Olhe, depende do ponto de vista de cada um, eu vejo que eu viajo também o pessoal não fala só de hippie, aqui tem muito gringo, eu não convivo com gringo e também não convivo com hippie, não é assim do meu convívio social, então eu não posso dizer, falando de imagem eu não vejo esta coisa toda não, essa coisa hippie.

Já M. T. Diretor da Associação de Condutores de Visitantes do Vale do Capão (ACV-VC) que atuava diretamente com o turismo e sobrevivia financeiramente da renda turística, afirmou que apresentava aos turistas a imagem do Capão como um local rural e com muita cultura e história.

\begin{abstract}
Eu pessoalmente gosto muito de botar a raiz local mesmo né, falando sobre a cultura do lugar, a forma como as pessoas vivem o dia aqui, os moradores e tal, e esse lado meio pra ambientação que chegou e entrou dentro daquilo que já existia aqui que era aquela cultura mesmo nativa de plantar, do garimpo, das festas tradicionais, meio desse tipo. As pessoas, eu acho que sabem realmente a origem do lugar.
\end{abstract}

\title{
6 DE ONDE VEM A PUBLICIDADE DE SOCIEDADE ALTERNATIVA?
}

Mas então de onde vinha esta fama de lugar alternativo? O que se percebeu entre as respostas dos moradores locais e as respostas dos turistas é que existia uma divergência de imagens. Aos olhos da comunidade local o Vale do Capão estava se apresentando como um destino turístico, porém negavam a imagem do local como um destino alternativo.

Analisando guias turísticos, reportagens e o site da Secretaria de Turismo da Bahia percebeu-se uma divulgação do Vale do Capão como um local para hippies. Se estava sendo esta a imagem vendida, então seria esta a imagem que os turistas iriam 
procurar, uma vez que chegavam ao destino final influenciados por esta imagem e iriam propagá-la quando retornassem para seus locais de origem.

A divulgação do Vale do Capão como um lugar alternativo, encantado, místico e esotérico foi percebida tanto nas placas de sinalização turística, quanto na sexta edição do Guia Turístico Chapada Diamantina (2014) e na website do Governo da Bahia. Na placa de sinalização turística localizada na cidade vizinha de Seabra, constatou-se que o Vale do Capão estava sendo apresentado como:

\begin{abstract}
Vale do Capão.
Está situado a $20 \mathrm{~km}$ de Palmeiras, a 1.000 metros de altitude. É um imenso e fértil vale, que fica entre as Serras do Candobá (no lado ocidental) e a da Larguinha e o Morro Branco (no lado oriental). O vale tem cerca de 12 quilômetros de largura e 8 quilômetros de extensão, que é cortado pelo Rio Capão e por vários córregos. Próximo ao vale encontra-se a Vila de CaetéAçu, que significa 'Grande Mata', reduto e ponto de encontro de pessoas alternativas, provenientes de várias regiões do Brasil e exterior, que procuram por paz e tranquilidade.
\end{abstract}

A sexta edição do Guia Turístico Chapada Diamantina (2014) apresentou o Vale do Capão como "O Vale Encantado". Já o Guia Turístico online da Chapada Diamantina (2015) apresentava o Vale do Capão como:

O Vale do Capão é uma atração por si só. Localizado no limite do Parque Nacional da Chapada Diamantina, ele é mais do que um santuário ecológico: é um lugar fascinante! O clima de esoterismo e paz está presente no dia a dia da comunidade e foi trazido por jovens ainda embalados pelos sonhos dos anos 70. Hoje, muitas pessoas continuam chegando dos grandes centros urbanos e até de outros países, à procura de autoconhecimento, espiritualidade, contemplação e uma vida mais sustentável.

É possível fazer os tradicionais passeios de ecoturismo no Capão e ainda provar delícias locais, como o pastel de palmito de jaca e a pizza integral, além de boas opções para vegetarianos. O local está repleto de estabelecimentos que oferecem práticas terapêuticas e tratamentos holísticos. Há acesso para alguns dos lugares mais famosos da região, como a Cachoeira da Fumaça e o Morrão. (GUIA CHAPADA DIAMANTINA, 2015)

A website do Governo da Bahia (2015) estava apresentando a Chapada Diamantina, e consequentemente o Vale do Capão, como um lugar de prática do ecoturismo "seja para a contemplação da natureza ou mesclado com a prática de esportes radicais e de aventura ou com fins místico e esotérico".

Verificou-se portanto, a existência de uma publicidade oficial que apresentava o Vale do Capão como um lugar místico e alternativo à sociedade de consumo, existindo 
uma demanda específica para este segmento, mesmo que a comunidade local não fizesse parte e nem estivesse de acordo com a divulgação desta imagem.

Entretanto, uma vez que a divulgação foi feita e vendida oficialmente, a imagem do Vale do Capão como um local alternativo, místico e esotérico estava sendo disseminada no dia a dia, podendo inclusive beneficiar a comunidade local que poderia passar a oferecer produtos e serviços que reforçassem essa imagem, como massagens, aulas de yoga etc., conforme verificado na figura 1 abaixo.

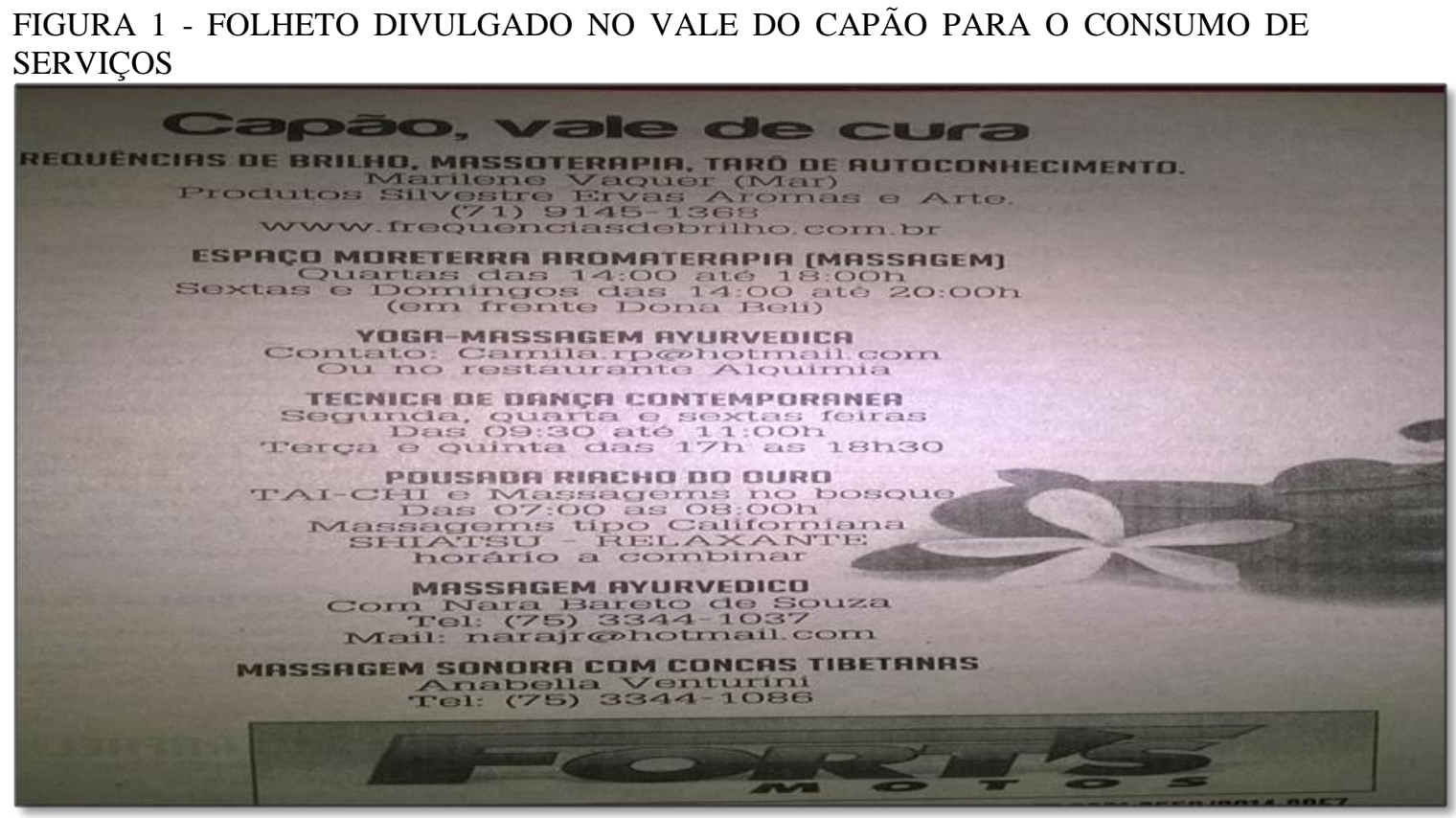

FONTE: Boas notícias do Capão, Jornal bimensal, n. 3, Fevereiro de 2012.

Por outro lado essa imagem estava contribuindo para estigmatizar o local e seus moradores, conforme se percebeu no relato considerado estereotipado e preconceituoso de um turista que divulgava sua experiência no Vale do Capão em um blog na internet, conforme segue abaixo:

A cidade do Vale do Capão é um lugar muito diferente. E quando digo diferente, digo alternativo. Ali era o paraíso dos bichos grilos. E quando digo bicho grilo não digo aqueles caras que ficam na Sé vendendo pulseiras. Os bichos grilos do Vale do Capão são gente rica, bonita, com dentes brancos e cabelos bons, que resolveram largar tudo e virarem bichos grilos fazendo artesanato e fumando maconha.

Vale do Capão é um lugar bem romântico para ir a dois. Em compensação, no que diz respeito a pegação e afins, devo dizer que a cidade não é de todo o mal. Existe uma programação noturna de forró e outros shows, e as meninas de lá eram extremamente bonitas, com dreads, tattoos, etc. entretanto, tenho 
certeza que a maioria delas conseguiria fazer um tererê no meio das pernas graças á falta de depilação. Se você curtir essas coisas lá vai ser seu paraíso. Afinal tem gosto pra tudo, não é? (A VIDA A PASSEIO, 2014).

\title{
7 O DOCUMENTÁRIO “PRA LÁ DO MUNDO"
}

No ano de 2013 foi lançado um documentário "Pra lá do mundo" com duração de uma hora e vinte minutos, que traz como foco a vida alternativa no Vale do Capão, conforme sinopse do filme:

\begin{abstract}
Um lugar deslumbrante cheio de magia, um Vale escondido a 1000 metros de altitude, na região da Chapada Diamantina, onde pessoas de diferentes nacionalidades buscaram refúgio, deixando grandes centros urbanos para uma ruptura radical com a sociedade de consumo. O local transformou-se em um centro de experimentação, diversidade e conflitos ideológicos, que ao mesmo tempo encantam, ameaçam e questionam o futuro da comunidade. (PRÁ LÁ DO MUNDO, 2013).
\end{abstract}

O documentário mostra o Vale do Capão como um lugar escondido entre as montanhas com pessoas alternativas à sociedade de consumo e como um lugar encantado, através da existência de uma "magia". Analisando o documentário percebeuse que das dezessete pessoas entrevistadas no filme apenas três eram moradores locais nascidos no Vale do Capão, o restante eram turistas. Este longa metragem foi apresentado nacionalmente em diversas salas de cinema e festivais nacionais e mostra uma imagem social do Vale do Capão, criado pelas pessoas "de fora". Durante todo documentário, enquanto os entrevistados vão relatando suas experiências de vida, surgem imagens de eventos privados místicos como o Santo Daime e Danças Sagradas, que a partir do que foi observado não se relacionam com as imagens reais e cotidianas do Capão.

O Vale do Capão apresentado neste documentário é um "Capão Hippie”, um lugar onde as pessoas pintam o rosto e fazem danças circulares ao redor de uma árvore, e, por este motivo, ficaram relacionadas ao cotidiano dos moradores. Com isso, a imagem do Capão hippie, esotérico, alternativo e místico passou a ser amplamente divulgada. 


\section{OS MORADORES E OS TURISTAS, ONDE ESTÁ O CONFLITO?}

Constatou-se que os moradores do Vale do Capão se beneficiavam do turismo de modo direto ou indireto. Dos moradores entrevistados todos estavam inseridos no mercado turístico, seja como provedores do ramo plenamente do turismo (guias de turismo ou proprietários de meios de hospedagem, no caso), seja como provedores do ramo que prestava serviços turísticos (proprietários de lojas e restaurantes, por exemplo). $\mathrm{O}$ que se percebeu foi uma grande dependência em relação à atividade turística, muitos moradores trocaram inclusive de profissão, a exemplo de N., que antes era um agricultor e passou a ser condutor de visitante capacitado, assim como M. antes pedreiro - e E. - antes dona de casa - e posteriormente proprietários de uma pousada e de uma loja de vestuário.

Quando perguntado aos moradores como eles percebiam o turismo no Vale do Capão, a maioria demonstrou uma receptividade à atividade econômica no local, todos gostavam do turismo no lugar, porém houve algumas controvérsias, como destacou E.:

\footnotetext{
Algumas coisas sim que acontece, mas não é o todo turismo, mas o melhor de tudo é que o turismo traz trabalho, muitas coisas boas também né, e como todo mundo aqui gosta. Claro que tem algumas coisas que todo mundo se preocupa, como assim que não tem jeito, uma coisa sai trazendo a outra como as drogas, isto é uma grande preocupação da comunidade.
}

M. também concordou e adicionou:

Há um lado positivo e negativo, mas no geral soma mais. Então eu acho que
o lado positivo é mais forte porque eu acho que no Capão hoje é assim, todo
mundo vive do turismo ou direto ou indiretamente, se você trabalha pra mim,
você trabalha pra mim porque eu trabalho com o turismo. Todo mundo acaba
vivendo daquilo porque é aquilo que gera emprego, gera renda no lugar. O
mercadinho vive do turismo porque o turista compra e o pessoal daqui ganha
dinheiro com o turismo e gasta no mercadinho.

Todos os moradores entrevistados deixaram claro que gostavam do turismo, porém salientaram que o mesmo era "uma faca de dois gumes", ou seja, tinha o lado positivo e o lado negativo. Todos eram a favor da atividade, contudo tendo seus pontos contraditórios, conforme o relato de D.: "parte positiva e parte negativa, não gosto do turista que acha que pode fazer o que quiser". Outro relato sobre o turismo é o de V.: 
Consciente sim, turismo consciente sim que normalmente são as pessoas de fora, turismo local é péssimo, soteropolitano só vem aqui pra deixar um monte de lixo, é aí que vem a imagem de Capão aldeia hippie que pode fumar em qualquer canto, pelo soteropolitano, é essa a imagem que eles saem aí falando pela internet a fora (entrevista realizada em 05/01/2016).

Os moradores alegaram sempre um bom relacionamento com os turistas, contudo o termo "bom relacionamento" variava de acordo com o tipo de turista, conforme o relato de C.: "eu gosto e não gosto. Tem o turista bom e tem turista ruim né em todos os cantos. Turista bom é o turista que não suja, que vem pra gastar é o mais importante".

A última pergunta feita aos moradores locais foi o que mais incomodava em relação ao turismo na região. As respostas obtidas destacaram três situações: drogas ilícitas, lixo e desrespeito às normas sociais.

Sobre o uso de drogas ilícitas o que incomodava a comunidade local era a utilização em locais públicos, como relata E.:

Quando tem festa é fumaça de maconha mesmo, é uma falta de respeito que todo mundo aqui queixa numa só voz sobre isso, porque mesmo que eles fumem que não vai ter jeito, a gente não vai impedir? Mas deveria procurar um lugar mais reservado para que eles pudessem ficar a vontade fumando que ninguém vai impedir, mas não, eles jogam fumaça no rosto da gente.

N. corroborou com as observações de E. e culpou os turistas sobre o uso de drogas ilícitas no Vale do Capão:

Esse turismo que vem muito farrento que gosta de usar, que traz vários tipos de drogas da cidade que não existia aqui, isso foi implantado em vários jovens daqui, vários nativos daqui. Então é um turismo que vem farrear e procura vim todo ano sabe, não é aquele turista que vem uma semana e visita e vai embora.

O lixo foi outro tema bastante citado nas entrevistas. No Vale do Capão verificou-se existir a cultura de apenas se jogar o lixo seco no jirau (tipo de suporte utilizado pelos moradores para colocar o lixo seco na rua para posterior coleta do caminhão), já o lixo orgânico era depositado em composteiras localizadas no quintal das residências. O que se percebeu durante os períodos de alta temporada foram lixos misturados e espalhados por vários locais, conforme se verifica na figura 2 a seguir: 
FIGURA 2 - RUA COM LIXO NA ALTA TEMPORADA DO FINAL DO ANO DE 2014.

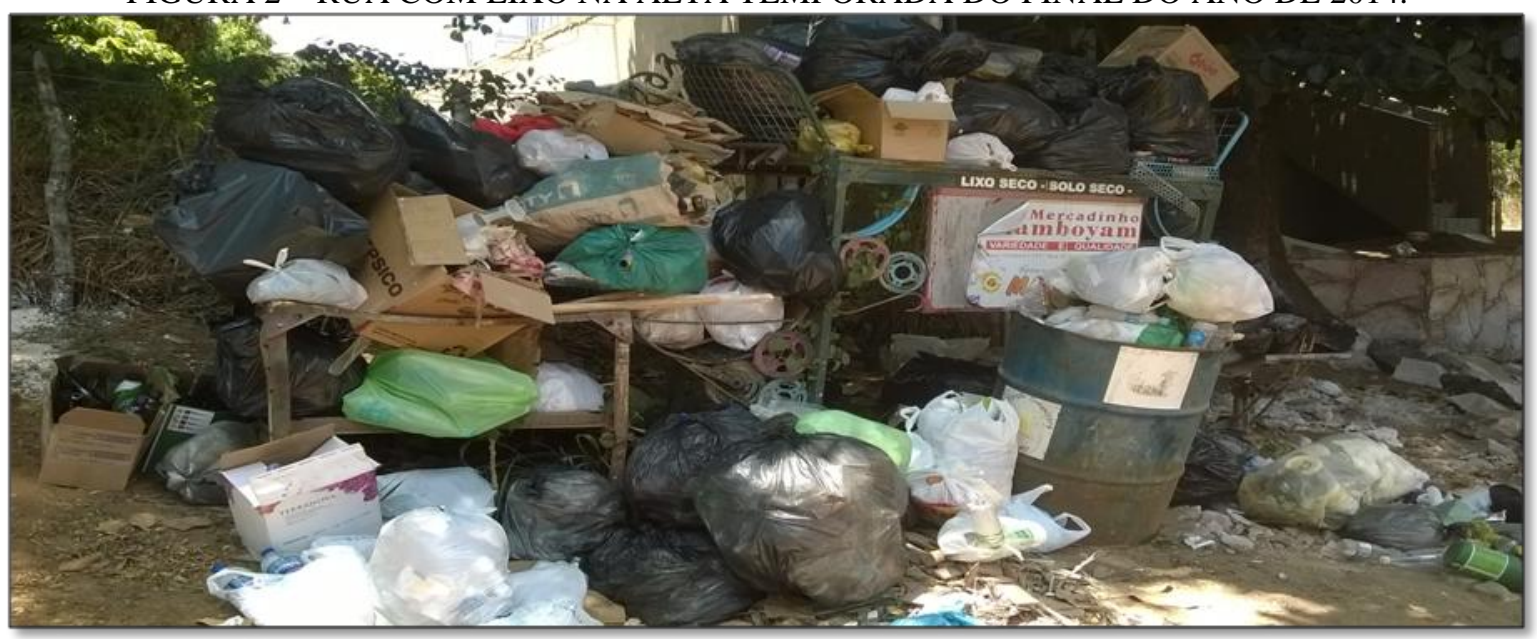

FONTE: Pesquisa de campo (2015-2016).

Esta situação estava incomodando os moradores, pois o lixo seco e orgânico ficava espalhado pelas estradas, praças públicas e até nos rios, conforme ressaltou a moradora V.: "falta de conscientização com o próprio lixo, ir para o rio, se encher de protetor solar e ainda querer tomar banho de sabão, isso acontece!’. Outra moradora, H., diretora da Associação de Moradores, Educadores e Agricultores de Caeté-Açu (APEACA) também ressaltou que "o turista não tem preocupação nenhuma em relação ao lixo, é uma tristeza porque eu já vi pessoas jogando lixo no meio do caminho, na frente da loja, andando no meio da rua e joga".

Outro tipo de comportamento do turista também muito questionado pelos moradores locais foi "sem muitas regras e sem muita conduta de boa estadia", conforme relato do morador C.: "tudo folgado, tudo relaxado, acha que o Capão é a casa da mãe deles". A moradora D. também afirmou: "o turista que acha que pode tudo, tipo o pessoal do Universo Paralelo (Festival de música eletrônica de dez dias que ocorre durante o Réveillon no litoral da Bahia, após o Festival muitas pessoas costumam seguir viagem para o Capão) que vem e acha que é terra de ninguém”. O morador T. também reclamou do comportamento dos turistas:

Nós aqui era assim, nós pegava cacho de banana levava pro Lençóis, jaca pra vender, banana pra comprar alguma coisa pra poder comer e depois que os turistas veio pra aqui melhorou foi muito, todo mundo de uma maneira, só quem não melhorou aqui são os preguiçosos. Antigamente o mais de dinheiro que se ganhava na inchada era quatorze conto, mas tinha uma coisa: um bom inchadeiro ganhava quatorze conto na inchada, mas também a despesa era toda na venda, mas agora aqui está bom graças a Deus. Só tem uma coisa que eu vou dizer o lugar quando tem muito progresso vem muita gente ruim, tem 
bom e ruim que um lugar que vem dinheiro vai vim qualquer malandro vagabundo.

Os turistas entrevistados para esta pesquisa foram questionados sobre a motivação da visita ao Vale do Capão e sobre a utilização (ou não) dos serviços turísticos disponíveis no local, todos os entrevistados destacaram o Vale do Capão como um lugar de descanso, sendo este o principal motivo da viagem, seguindo da apreciação ao ecoturismo. Nove dos dez turistas entrevistados utilizaram os serviços turísticos do local: hospedagem, transporte ou serviço de condutores. A única exceção foi do turista C. que afirmou ter chegado ao local por acaso, por convite de uma amiga na estrada, quando perguntado sobre a utilização de serviços do trade turístico, comentou: "não, não utilizei nada, até o transporte foi de carona e metade do caminho foi andando mesmo, eu vim lá de Palmeiras, tipo, um pedação andando".

Sobre o relacionamento dos turistas com a comunidade local, sete dos dez visitantes confirmaram que tinham boas relações com os moradores, duas turistas alegaram não conhecer ninguém, pois haviam chegado ao local há pouco tempo, apenas um entrevistado (turista C.) se mostrou avesso ao relacionamento com os moradores:

Tá ligado que quem vem trabalhar também eles não curtem não. Porque tipo assim, os caras não gostam, tá ligada? Às vezes a gente está num lugar trocando ideia e ai chega alguém falando merda, a gente está na beira do rio e eles falam um monte de besteiras pra gente, que a gente vem só sujar, só fala merda... Eles não gostam cara! Ah! Tipo, eu conheço algumas pessoas que são gente boa, claro, claro que eu generalizei um pouco, mas boa parte da galera não gosta, tá ligado!

Para os turistas também foi questionamento como eles se posicionavam em relação às regras de convívio do local. Todos os dez entrevistados responderam que estavam bastante conscientes em relação ao respeito com as regras de convivência, embora esta afirmação seja divergente do relato dos moradores. A compreensão sobre estar em um lugar que não é o seu se mostrou presente nas entrevistas com todos os turistas, conforme afirma a turista J.: "isso é questão de respeito, aqui tem criança, tem gente idosa. Algumas pessoas que a gente conheceu por aqui nos disseram que não é legal ficar fumando essas coisas na calçada e tal, então a gente não fez". Já o turista C. destacou: 
Claro, sempre, é porque tipo assim: é porque já vem outras pessoas que viajam e deixam a má fama, aí quando eu acho que eles vem uma pessoa que tá vindo, eu acho que eles já tipo um preconceito por causa disso, por causa de outras pessoas que já vieram e já deixaram má impressão. Tem que respeitar, a gente está no espaço deles também, o espaço da comunidade, isso aí a gente tem procurar respeitar sim, o ambiente é de todos.

Durante todas as entrevistas realizadas, sobretudo com os moradores locais, o que se percebeu é que havia uma confusão de conceitos sobre a segmentação do turismo (ecoturismo, turismo de natureza, turismo esotérico, turismo místico, turismo alternativo) e sobre o tipo/perfil de turista no Vale do Capão (ecoturistas, turistas de natureza, turista de aventura, turista esotérico, turista místico, turista alternativo). Essa confusão de conceitos foi observada tanto pelos moradores, quanto pelos próprios turistas que visitavam o local, alguns, inclusive, se autodenominaram como turista esotérico sob o pretexto de "fazer o que bem quer" e para dizer que ali se poderia fazer coisas que não faziam cotidianamente no seu lugar de moradia. Neste contexto é importante destacar as observações feitas por Viana (2012, p. 45) de que quando se viaja, busca-se pelo "lugar dos sonhos, onde se possa realizar tudo aquilo que a vida diária e habitual reprime".

\section{CONSIDERAÇÕES FINAIS}

Pode-se afirmar que a imagem social e a imagem real divulgada sobre o Vale do Capão estava influenciando a vinda de turistas que procuravam no Vale do Capão algo que muitas vezes não correspondia ao que era vivenciado cotidianamente pelos moradores locais. Essa situação frustrava as perspectivas dos moradores em relação ao desenvolvimento da atividade turística, trazendo como consequência uma imagem negativa dos turistas, apesar de perceberem o turismo como algo positivo para o local.

Significa dizer que para os moradores do Vale do Capão o turista bom era aquele que contribuía economicamente para a região, seria o ecoturista, o turista que buscava atrativos naturais, turismo de natureza, e contribuía ambientalmente para o local. O turista ruim era denominado como o turista hippie, aquele que estava vindo por conta própria, que fazia uso de poucos serviços locais, que trazia uma imagem social do Capão como um local alternativo, sem regras e permissivo. 
Neste sentido, se percebeu que o Vale do Capão estava vivendo um turismo híbrido, onde práticas de produção e apropriação simbólicas de diversas culturas estavam a mesclar-se à cultura local (SANTOS, 2009) e ambos agentes, moradores e turistas, estavam sendo responsáveis por tal acontecimento.

Seria preciso, contudo, definir que tipo/perfil de turista foco do desenvolvimento do turismo no Vale do Capão e qual segmentação do turismo que o lugar estava almejando, se ecoturismo, turismo de natureza, turismo de aventura, turismo esotérico, turismo místico, turismo alternativo. Se fazia preciso que essas fronteiras estivessem muito bem definidas para evitar esse conflito de imagem e de interesses difusos no destino. Isso não significa dizer que se deveria optar por um tipo/segmento/perfil de turismo ou turista, mas que seria necessário definir essas fronteiras, bem como a imagem turística do Vale do Capão, de modo que a atividade turística do local não ficasse prejudicada.

Por mais que os moradores locais criticassem o comportamento dos turistas, eles também foram corresponsáveis pela situação, uma vez que pensando apenas na receita turística, deixaram de estabelecer algumas limitações ao uso do lugar, a exemplo do lixo.

Considerou-se ser necessário que os segmentos turísticos estivessem mais bem trabalhados pela gestão pública, trade, marketing e moradores locais, a fim de que não existissem tratamentos errôneos e pejorativos aos visitantes (e vice-versa). Através disso a atividade turística seria orientada para atrair os turistas desejados, fossem eles esotéricos, místicos, alternativos ou ecoturistas, evitando um desconforto e uma divergência entre a imagem real e a imagem social do destino turístico, e, sobretudo, minimizando incidentes e conflitos entre turistas e moradores locais, pois uma cidade só será boa para o turista se for boa para a comunidade, ou seja, "pra lá do mundo, existe um mundo em comum".

\section{REFERÊNCIAS}

A VIDA A PASSEIO, 2014. Disponível em: <http://avidaapasseio.blogspot.com.br/2014/01/chapado-na-chapada-diamantina.html>. Acesso em: 20/01/2016. 
BARDIN, L. Análise de Conteúdo. Lisboa, Portugal; Edições 70, LDA, 2009.

BARRETTO, M. Turismo y cultura relaciones, contradicciones y expectativas. Espanha: Aca y Passos, 2007.

BENI, M. C. Análise Estrutural do Turismo. São Paulo: Editora SENAC, 2002.

BRYDEN, J. Tourism and Development: A case study of the Commonwealth Caribbean. Cambridge: Cambridge University Press, 1973.

COHEN, E. Arab Boys and Tourist Girls in a Mixed Jewish-Arab Community. In: International Journal of Comparative Sociology, v. 12, n. 4, 1971, p. $217-233$.

FONSECA, R. C. V. da. Metodologia do Trabalho Científico. Curitiba: IESDE Brasil S.A., 2009.

GOVERNO DA BAHIA, 2015. Disponível em: <http://bahia.com.br/segmentos/ecoturismo>. Acesso em: 20/01/2016.

GRABURN, N. Antropologia ou antropologias do turismo? In. GRABURN, N.; BARRETTO, M.; STEIL, C. A.; GRUNEWALD, R. A.; SANTOS, R. F. Turismo e antropologia novas abordagens. São Paulo: Papirus, 2009. p. 13-40.

GUIA CHAPADA DA DIAMANTINA, 2015. Disponível em: $<$ http://www.guiachapadadiamantina.com.br/cidades-e-vilas/cidades-e-vilas-vale-do capao>. Acesso em: 20/01/2016.

KRIPPENDORF, J. Sociologia do turismo: para uma nova compreensão do lazer e das viagens. 2. ed. São Paulo: Aleph, 2001.

MAANEN, J. V. Reclaiming qualitative methods for organizational research: a preface. Administrative Science Quarterly. v. 24, n. 4, December, 1979, p. 520-526.

NASH, D. Anthropology of tourism. Kidlington, Oxford: Pergamon; Tarrytown, N.Y.: Elsevier Science, 1996.

NOGUEIRA, A. C. C. Nativos, alternativos e crescimento urbano: Vale do Capão Chapada Diamantina - BA - 1983-2003. Monografia (Graduação em Urbanismo) Universidade Estadual da Bahia, Bahia, 2003.

NUÑEZ, T. Tourism, tradition and acculturation: weekendismo in a Mexican Village. In: Ethnology, v. 2, n. 3, 1963, p. 347-352.

PRÁ LÁ DO MUNDO, 2013. Disponível em: <https://www.facebook.com/PraLaDoMundo/info/?entry_point=page_nav_about_item \&tab=page_info $>$. Acesso em: 20/01/2016. 
PRODANOV, C. C.; FREITAS, E. C. de. Metodologia do Trabalho Científico: Métodos e Técnicas da Pesquisa e do Trabalho Acadêmico. Novo Amburgo: Feevale, 2013.

SANTOS, R. Hibridação cultural e turismo. In. GRABURN, N.; BARRETTO, M.; STEIL, C. A.; GRUNEWALD, R. A.; SANTOS, R. F. Turismo e antropologia novas abordagens. São Paulo: Papirus, 2009. p. 119-139.

SMITH, V. L. Hosts and guests: the anthropology of tourism. 2. ed. Philadelphia: University of Pennsylvania Press, 1989.

TAVEIRA, M. da S. Identidades cultural e turística de São Miguel do Gostoso, Rio Grande do Norte (RN), Brasil. In: Turismo \& Sociedade. Curitiba, v. 9, n. 1, janeiroabril de 2016, p. 1-22.

URRY, J. O olhar do turista lazer e viagens nas sociedades contemporâneas. 3. ed. São Paulo: Studio Nobel, 1996.

VIANA, M. F. Com vista para o mar: sobre a produção da imagem da Fortaleza vendável (Ceará, Brasil). In: Turismo \& Sociedade. Curitiba, v. 5, n.1, abril de 2012, p. 37-57.

YOUNG, G. Tourism: Blessing or blight? Harmondsworth: Penguim, 1973.

Recebido em: 10-10-2017.

Aprovado em: 09-11-2017. 